\title{
Emergências globais e suas implicações para a formação e prática do enfermeiro na atenção à saúde da criança e do adolescente
}

$\mathrm{D}$ esde o início de 2020 estamos vivendo num mundo de incertezas, enfrentando a primeira pandemia do século XXI, causada pelo vírus SARS-CoV-2 e denominada doença do coronavírus 2019 (COVID-19), caracterizada como uma infecção respiratória aguda potencialmente grave, denominada síndrome respiratória aguda grave. ${ }^{(1)}$

Em decorrência dessa grave ameaça a saúde dos seres humanos em escala planetária, muitas medidas foram impostas na tentativa de minimizar seus efeitos e mitigar sua propagação, tais como: o isolamento social, a lavagem das mãos com frequência e, na impossibilidade dessa prática, a higiene com o uso de álcool a 70\% em gel, cobertura do nariz e da boca com máscara para sair à rua, evitar o contato próximo com outras pessoas, principalmente em locais públicos, manutenção de distância mínima de um a dois metros, higiene respiratória, permanência em casa na presença de sintomas respiratórios, limpeza e desinfecção frequentes das superfícies de contato com potencial de contaminação, dentre outras. ${ }^{(2)}$

Some-se ao fator pandemia suas consequências para além do setor saúde, como as iniquidades entre países no acesso a imunização, os efeitos econômicos em função dos períodos de isolamento social e fechamento de fronteiras, os setores afetados por dependência de público que deixaram de existir e por conseguinte os empregos que geravam, todos considerados determinantes sociais do processo saúde-adoecimento, impactando famílias e comunidades no mundo todo. ${ }^{(3)}$

A instabilidade social, ambiental e política ao redor do mundo tem gerado ainda uma outra epidemia, a da imigração forçada dos povos para longe de seus locais de origem, viajando em condições precárias e sem garantia de acesso a outras realidades para viver a vida com dignidade. Neste cenário, a chegada de centenas de milhares de imigrantes refugiados, vindos de países em situações adversas, como Haiti e Venezuela, vivendo no Brasil em condições precárias, com comprometimento de suas vidas e de seus filhos, merece destaque. Todas essas são emergências globais que precisam ser debatidas pelo setor saúde. ${ }^{(4)}$

A Enfermagem Pediátrica e Neonatológica brasileira não se furtou a refletir sobre essa realidade. Ao propor a realização de modo virtual de seu IX Congresso Brasileiro de Enfermagem Pediátrica e Neonatal, realizado em outubro de 2021, em consequência da pandemia da Covid-19, adotou como tema central e que dá título a esse editorial, as emergências globais e suas implicações para a formação e prática do enfermeiro na atenção à saúde da criança e do adolescente.

Os temas que perpassam o tema central foram debatidos em três dias de evento: Assistência integral e prática interprofissional à saúde do neonato, da criança, do adolescente e família nos diferentes níveis da rede de atenção à saú- 
de; Produção e aplicação do conhecimento; e, Implicações das tecnologias em enfermagem neonatológica e pediátrica.

O evento teve início com a conferência de abertura denominada: Emergências globais e suas implicações para a formação e prática do enfermeiro na atenção à saúde da criança e do adolescente, proferida pela Dra. Julia Grant, do Conselho Nacional de Enfermagem da Austrália e coordenado pela Dra. Myriam Aparecida Mandetta, presidente da Sobep.

A programação foi desenvolvida com mesas de debates, conferências, apresentações de trabalhos, com temas abrangentes, os quais se apresenta em seguida.

Na mesa de debates Segurança do neonato, criança e adolescente em tempos de pandemia: aprendendo com a COVID-19 foram abordados os temas: A segurança do ambiente e do paciente pediátrico na perspectiva dos profissionais; A segurança do paciente pediátrico na perspectiva dos gestores, Desafios na continuidade do cuidado das crianças e adolescentes com condições crônicas e demandas especiais de cuidados em tempos de pandemia; e, A segurança do paciente pediátrico na perspectiva da família (O olhar da família e da criança sobre a proteção e segurança recebidos no cuidado de Enfermagem durante hospitalização no período de pandemia).

Outra atividade foi denominada Experiências no cuidado do neonato, criança e adolescente, incluindo temas como: Tecnologia educativa como ferramenta de divulgação do conhecimento em enfermagem; Caminhos para a comunicação efetiva com a criança/adolescente e a família nos cenários de cuidado; Pesquisas colaborativas (repositórios de dados): experiências na enfermagem neonatológica e pediátrica; e, O cuidado de Enfermagem as mães e RN em tempo de pandemia.

Discutiu-se em conferência sobre a Adesão à imunização em tempos de pandemia por SARSCov2, além de mesa de debates intitulada Imunização em crianças diante das emergências globais: novos e velhos desafios incluindo temas como: Ensaios clínicos com crianças (necessidade, questões éticas) e o uso de imunizantes; Diferentes contextos de emergências globais (crenças familiares sobre a aplicação de vacinas: imigração, diferenças culturais, étnico-raciais); e, Melhores práticas em imunização.

Um novidade na edição do congresso Sobep em 2021 foram os mosaicos com famílias, em que estas gravaram vídeos dando voz a suas experiências sobre os distintos temas abordados no evento, apresentados nas mesas de debates respectivas, como contextos de famílias/narrativas das famílias sobre a vacinação das crianças, sobre experiências de prevenção, sobre as tecnologias da informação como ferramentas de comunicação, por exemplo.

Mediante um cenário de adversidades, é importante debater sobre as Competências para o cuidado da criança e do adolescente em cenários de crise, para tanto, essa mesa de debates trouxe temas como Ações de cuidado na primeira infância frente a pandemia: impactos na socialização da criança; Promoção da saúde mental na infância e adolescência em cenários de crise; Desenvolvimento de competências para o cuidado da criança e do adolescente e família (CCPF) em cenários de crise; e, A essência do brincar durante a pandemia, o lúdico no cuidado.

O debate Justiça social, políticas públicas e a garantia dos direitos das crianças diante das emergências globais foi um marco do evento, promovendo importante reflexão acerca do momento vivido e suas consequências para a infância. Nesse 
sentido, seguiu-se mesa de debates sobre a Prevenção de riscos para proteção de crianças e adolescentes em tempos de pandemia, incluindo temas como a Violência na infância e adolescência durante o período de pandemia; Pesquisa e cuidado nos acidentes na infância e adolescência durante o período de pandemia; e, Cuidado a crianças e adolescentes em contexto de vulnerabilidade: indígenas, quilombolas, imigrantes.

O cuidado dos profissionais de enfermagem não foi esquecido no IX CBEPN, com a mesa coordenada versando sobre $O$ cuidado de quem cuida durante o período de pandemia, a qual abrangeu os temas Enfrentando o medo e demonstrando coragem: a resiliência moral do enfermeiro pediatra frente às emergências de saúde de abrangência global; A saúde mental dos profissionais de enfermagem que atendem neonatos, crianças e adolescentes no período de pandemia; e, $\mathrm{O}$ cuidado emocional na enfermagem pediátrica: a gestão da emoção durante a pandemia.

Um diferencial do cuidado nesse período foi a teleassistência, inclusive para a enfermagem. Assim, o tema foi tratado em mesa coordenada denominada $O$ fazer da Enfermagem diante da pandemia de Covid-19: assistência remota a família para o cuidar de crianças e adolescentes, com temas como a Consulta do enfermeiro pediatra à distância (possibilidades, vantagens e desvantagens, questões éticas, sigilo profissional, tipos de mídia, uso de imagens, registro das informações geradas); As tecnologias da informação como ferramentas de comunicação (cuidado, monitoramento) do enfermeiro pediatra com a criança e a família (aplicativos, apoio ao profissional para o uso apropriado das ferramentas); e, A tecnologia da informação como ferramenta de disseminação do conhecimento em saúde frente às emergências globais.

Outro enfoque tratado foi A pesquisa da enfermagem pediátrica e neonatológica no Brasil em tempos de pandemia, em que se discutiram temas como as Tendências e desafios para a pesquisa com neonatos, crianças, adolescentes e famílias no período de pandemia (temáticas pesquisadas, agendas de investigação, potencialidades para o uso de recursos, observatório de pesquisa com crianças, inteligência artificial na tomada de decisão, dificuldades para pesquisa de campo); Tecnologia de informação e comunicação para pesquisas com crianças e adolescentes e família (novos estratégias de pesquisa, recursos para produção do conhecimento, subsidiar tomada de decisões); e, Translação do conhecimento: contribuições para a prática de enfermagem neonatológica e pediátrica mediante as emergências globais atuais (aspectos metodológicos e práticos).

Na mesa coordenada sobre Atualizações para a prática do enfermeiro pediatra e neonatologista, foram enfocados temas como Manuseio do cateter de PICC, Sondagem gástrica e vesical; Contenção da criança; Protocolos de cuidado na assistência à criança com câncer no período da pandemia de Covid-19; e as Competências do Enfermeiro Pediatra e Neonatal, produzidas pela Sobep em 2019 e apresentadas aos participantes do evento, pois, para a gestão de cuidados de Enfermagem nessas circunstâncias, exige-se a formação de enfermeiros especialistas com competências que lhes permitam desenvolver ações abrangentes.

Além disso, foram recebidos aproximadamente 600 resumos de trabalhos científicos, apresentados na forma de comunicação oral e poster virtual, divulgando a produção de conhecimento da área de enfermagem pediátrica e Neona- 
tológica. Também foram realizados fóruns importantes como o de pesquisa e das residências, com encaminhamos para o futuro, como a criação de um espaço de divulgação da produção do conhecimento na página da Sobep e a realização de encontros de residências periodicamente. Além destes, foi realizado o fórum da pesquisa: produção do cuidado e validação de protocolo de fluxo para serviços de atenção domiciliar a CRIANES.

Na conferência de encerramento, a Dra. Myriam Aparecida Mandetta trouxe a reflexão sobre os Impactos da pandemia COVID-19 em crianças e adolescentes: lições que aprendemos (aspectos positivos como higienização das mãos, negativos: ausência da escola, isolamento, não adesão aos cuidados, educação da criança para a saúde, a família e sua relação com a criança).

Ademais, em todas as edições do evento aplica-se a concurso público para Obtenção do Título de Especialista pela SOBEP. Nessa ocasião, pela primeira vez, a prova foi online, o que permitiu a participação de enfermeiros de todo o país, ampliando-se a procura pela obtenção da titulação em Enfermagem Pediátrica e Enfermagem Neonatológica.

A premiação dos melhores trabalhos apresentados em comunicação oral e das menções honrosas abrilhantou a cerimônia de encerramento e deixou em todos os participantes a esperança de nos reencontrarmos em um próximo evento Sobep, já tradicionalmente realizado a cada dois anos.

\section{Referências}

1. Ren LL, Wang YM, Wu ZQ, Xiang ZC, Guo L, Xu T, et al. Identification of a novel coronavirus causing severe pneumonia in human: a descriptive study. Chin Med J (Engl). 2020;133(9):1015-24.

2. Brasil. Ministério da Saúde. Coronavírus COVID-19. Boletins Epidemiológicos. Brasília (DF): Ministério da Saúde; 2020 [citado 2020 Ago 20]. Disponivel em: https://www.saude.gov.br/boletins-epidemiologicos

3. Souza D0. A pandemia de COVID-19 para além das Ciências da Saúde: reflexões sobre sua determinação social. Ciênc Saúde Colet. 2020;25(Suppl 1):2469-77.

4. Granada D, Carreno I, Ramos N, Ramos MC. Discutir saúde e imigração no contexto atual de intensa mobilidade humana. Dossiê: migração e saúde. Interface. 2017;21(61):285-96.

Beatriz Rosana Gonçalves de Oliveira Toso (1) https://orcid.org/0000-0001-7366-077x Universidade Estadual do Oeste do Paraná, Cascavel, PR, Brasil

Myriam Aparecida Mandetta (10 https://orcid.org/0000-0003-4399-2479 Escola Paulista de Enfermagem, Universidade Federal de São Paulo, São Paulo, SP, Brasil

DOI: http://dx.doi.org/10.31508/1676-379320210009

Como citar: Toso BR, Mandetta MA. Emergências globais e suas implicações para a formação e prática do enfermeiro na atenção à saúde da criança e do adolescente [Editorial]. Rev Soc Bras Enferm Ped. 2021;21(2):61-4. 